\title{
"CONTROLE DE CONSTITUCIONALIDADE UMA SUCINTA COMPARAÇÃO ENTRE O BRASIL E O JAPÃO"
}

\author{
Miyuki Sato \\ Professora, Pesquisadora e Visitante na Faculdade de Direito da \\ Universidade de São Paulo, nos termos do acordo celebrado com a \\ Universidade de Tóquio
}

Antes de começar esta pequena palestra, aproveitando esta ocasião, gostaria de agradecer a todas as pessọas, que me têm ajudado na realização da minha pesquisa no Brasil, especialmente a Diretora desta Faculdade, Dra. Ivette Senise Ferreira, que me deu esta grande oportunidade de fazer esta palestra, Dr. Masato Ninomiya, que aceitou ser responsável por minha permanência neste País, os meus orientadores Dr. Kazuo Watanabe, Dra. Giselda Maria Fernandes Novaes Hironaka e Dra. Ana Cândida da Cunha Ferraz, os juízes e os advogados que consentiram generosamente no meu pedido de fazer entrevista, as bibliotecárias e funcionários do Serviço Técnico de Imprensa da Faculdade, que facilitaram meu estudo, e a minha família, que me tem apoiado sempre com plenitude.

Hoje, trouxe "o controle de constitucionalidade" como o tema da palestra. Contemplando minha posição como uma pesquisadora japonesa no Brasil, queria tentar fazer uma sucinta comparação entre as circunstâncias do Brasil e as do Japão com relação ao sistema.

Graças aos esforços dos descendentes dos imigrantes japoneses, o Brasil tem uma forte ligação emocional com o Japão e também bastante conhecimento sobre nosso país.

Apesar desta sorte, ainda surge um receio de dificuldade de comparação entre os sistemas dos dois países, pois geograficamente o Brasil é quase antípoda do Japão e pertence basicamente à cultura ocidental e, o Japão, tradicionalmente, à oriental.

Ao contrário desta aparente dificuldade, todavia, acredito que seja apropriada a comparação entre os dois países a respeito do controle de constitucionalidade, porque existem várias instituições jurídicas comuns em ambos os países.

Os sistemas jurídicos dos dois países são parte da família romanogermânica e, entretanto, na área de Direito Público, a presença dos EUA é significante. 
No controle de constitucionalidade, os dois possuem o sistema difuso, quer dizer, cabe à todos os tribunais o poder de examinar a inconstitucionalidade das leis ou dos atos normativos. Porém, o Brasil tem 110 anos de tradição do sistema, enquanto o Japão, 54 anos, isto é, a História brasileira do controle de constitucionalidade é duas vezes mais longa que a do Japão.

I. Agora, vamos dar uma rápida olhada nos sistemas de controle jurídico de constitucionalidade dos dois países.

Além do sistema difuso, o Brasil, atualmente, possui mais um sistema do controle, ou seja, o sistema concentrado, em que cabe o poder do exame de constitucionalidade a um único órgão.

Esta co-existência dos dois sistemas se chama "sistema misto" Entretanto, na época imperial, não havia nenhum controle judicial de constitucionalidade, pois a influxo da Europa, que desconfiava do poder jurídico e acreditava na supremacia do poder legislativo, era muito forte e, além disto, ao imperador, que possuía o poder moderador, foi dada a função de manter equilíbrio e harmonia dos demais poderes políticos.

À chegada da Primeira República, o Brasil adotou o controle judicial de constitucionalidade, ou seja, o sistema difuso, tomando o dos EUA por modelo.

Falando no Japão, tivemos duas Constituições até agora. Uma é a Constituição Imperial de Meiji e outra é a atual Constituição democrática.

No período imperial, sob a Constituição de Meiji, de 1889, que foi influenciada pelos países europeus, particularmente pela Prússia, nós não tínhamos o sistema de controle judicial de constitucionalidade.

Depois da derrota do Império japonês na Segunda Guerra Mundial, quem tomou a liderança da democratização do nosso país foram os EUA. Conseqüentemente, nós adotamos a Constituição nova, sob grande influência dos EUA e viemos a ter o controle judicial de constitucionalidade tipo americano, quer dizer, o sistema difuso.

Na nova Constituição japonesa, de 1947, há artigos que sugerem a adoção do sistema difuso manifestamente. $\mathrm{O}$ art. 81 dispõe o seguinte:

"A Corte Suprema é o tribunal de última instância que tem poder de determinar a constitucionalidade de qualquer lei, orden, regulamento ou ato oficial." E também o art. 98 diz:

"A Constituição será a lei suprema da Nação e nenhum regulamento, 
rescrito imperial ou outro ato do governo, ou parte dele, que contrarie suas estipulações terá força legal ou validade"

Por fim, sistematicamente falando, o controle difuso é comum em ambos os países. Contudo, ao passo que o Japão adota o Estado unitário, o Brasil, como país, cujo território é esmagadoramente enorme, adota o Federalismo, que foi um dos principais motivos da introdução do controle de constitucionalidade, seguindo o exemplo dos EUA, mesmo que o Federalismo brasileiro historicamente tenha se direcionado para a descentralização, ao contrário da finalidade centralizante do Federalismo americano.

A adoção do controle judicial de constitucionalidade das leis no Brasil avançou meio século sobre a do Japão. Durante esse meio século, o sistema difuso do Brasil sofreu uma grande mudança a respeito de seus efeitos. Passados vários regimes, inclusive ditadura e militarismo, o Brasil tem tido seis constituições, desde a Primeira República e esta substituição de constituições influenciou o sistema de controle de constitucionalidade.

Em 1934, a Constituição consagrou no Senado Federal o poder de suspender a execução das leis declaradas inconstitucionais pelo Supremo Tribunal Federal.

Ao mesmo tempo, a mesma Constituição abriu o caminho ao controle concentrado, pois adotou uma limitada ação de constitucionalidade no Supremo Tribunal Federal em relação à União e aos Estados-Membros, que se chama "representação interventiva"

Este sistema foi ampliado para o controle de constitucionalidade das leis em geral, incluindo leis federais, através da emenda constitucional de I965. Porém, naquela época do regime militar, somente o procurador-geral da República, que estava sob o controle do presidente da República, podia propor esta categoria de ação.

Pela Constituição de 1988, que foi elaborada para estabelecer um país democrático, os titulares que podem propor a ação de inconstitucionalidade foram multiplicados.

O sistema concentrado tem progredido e, ainda mais, em 1993 foi inovado o instituto da Ação Declaratória de Constitucionalidade.

II. Agora, vamos mudar nosso enfoque, da similaridade básica institucional entre os dois países para sua variedade.

Não-obstante tantas similaridades, os usos do instituto do controle de constitucionalidade do Brasil e do Japão são completamente diferentes. 
a. Em primeiro lugar, vamos começar com a observação geral e quantitativa.

O núcleo do controle de constitucionalidade encontra-se nos tribunais supremos de ambos países, os quais ficam no cume dọ Poder Judiciário.

As organizações e as competências dos Tribunais Supremos brasileiro e japonês não são iguais, portanto, não é possível uma exata comparação. Contudo, nós podemos fazer observação geral e comparativa pela sua evidente diferença quantitativa.

São da competência da Corte Suprema japonesa os recursos ordinários e os extraordinários. Os recursos ordinários incluem os casos de infração processual civil e de dissídio jurisprudencial penal, além de processos de argüição de constitucionalidade.

Ao invés, no Brasil, as competências do Supremo Tribunal Federal são mais amplas que as do Japão, porém, a respeito dos processos extraordinários, a matéria foi limitada à contrariedade à Constituição Federal, depois da criação do Superior Tribunal de Justiça pela Constituição Nova.

Então, a podemos comparar quantitativamente, para mostrar a diferença:

Enquanto 5.700 processos foram recebidos na Corte Suprema no Japão, em 1999, 68.369 processos foram recebidos no Supremo Tribunal Federal brasileiro. Em outras palavras, o número de processos do Supremo Tribunal Federal é quase doze vezes maior que o número da Corte Suprema japonesa.

b. Em segundo lugar, vamos ver a relação entre o Poder Judiciário e os outros poderes, especificamente o Poder Executivo.

A interpretação dos resultados das Ações Diretas de Inconstitucionalidade não é simples, mas, para perceber a relação entre o Poder Judiciário e os outros poderes, vale a pena fazê-la:

No Brasil, desde outubro de 1988, quer dizer, desde a data da promulgação da nova Constituição até junho de 1999, 2 mil Ações Diretas de Inconstitucionalidade foram processadas. A metade foi julgada quanto ao mérito.

Entre elas, nos 258 processos o Supremo Tribunal Federal julgou inconstitucionais as leis ou atos normativos, ou seja, 1/4 dos resultados dos julgamentos dos méritos obtiveram a declaração de inconstitucionalidade.

No Japão, durante 54 anos de experiência do controle judicial de constitucionalidade, apenas em uns cinco casos foi declarada a inconstitucionalidade das leis na Corte Suprema. 
c. Em terceiro lugar, vamos considerar a relação entre os Tribunais supremos e os Tribunais inferiores.

Nem no Brasil nem no Japão o princípio de "stare decisis" do sistema anglo-saxonico foi adotado.

Como resultado, no Brasil, durante a Primeira República, mesmo depois de declaração de inconstitucionalidade de leis pelo Supremo Tribunal Federal, dizem que os juizes dos tribunais inferiores, de vez em quando, julgaram constitucionais as mesmas leis.

Tão preocupante era essa situação, que a Constituição, de 1934, resolveu estabelecer um sistema inovador, que consagrou o poder de suspender a execução das leis declaradas inconstitucionais pelo Supremo Tribunal Federal no Senado Federal, a fim de evitar dissídios jurisprudenciais e insegurança jurídica.

E mais recentemente, em 1993, foi adotado o Instituto de Ação Declaratória de Constitucionalidade, que dá o efeito vinculante à decisão do Supremo Tribunal Federal.

No entanto, existiam e continuam a existir os dissídios entre as decisões dos Tribunais inferiores e as do Supremo Tribunal Federal.

No Japão, apesar da mesma situação de inexistência do princípio de "stare decisis" sua conseqüência é totalmente oposta.

Nessa mesma circunstância, a jurisprudência da Corte Suprema tem influenciado tão-profundamente os tribunais inferiores japoneses, que eles têm preferido julgar seguindo a decisão da Corte Suprema.

É quase impossível, para nós, imaginar que os tribunais inferiores exponham a constitucionalidade de uma lei, depois que a Corte Suprema houver declarado a inconstitucionalidade dessa mesma lei.

III. Baseados nestes fatos pressupostos, vamos avançar um pouco mais a análise.

a. Em primeiro lugar, temos que revisar o significado dos números dos processos anuais nos Tribunais Supremos dos dois países.

Parece que o Supremo Tribunal Federal do Brasil sempre está cheio de processos, mas, na verdade, não é bem assim. Na verdade, até a década de 50, o Supremo Tribunal Federal no Brasil havia recebido menos de 5 mil processos por ano, enquanto a Corte Suprema japonesa, sob a atual Constituição, tem recebido cerca de mesmo número de processos constantemente.

A causa importante do aumento dos processos no Supremo Tribunal Federal é a Nova Constituiçãcao. 
No Brasil, logo depois da criaçao do Superior Tribunal de Justiça, pela Nova Constituição, o número de processos recebidos no Supremo Tribunal Federal diminuiu; contudo, já o número do ano de 1992 superou o da véspera da promulgação da Constituição e agora se triplicou. O povo brasileiro, que estava contido durante 21 anos de regime militar, aprendeu, com muita rapidez, a requerer seus direitos com a democracia e, com a chegada da Constituição Cidadã, começou a praticá-los sem vacilação.

Vale a pena lembrar de que no Brasil existem cerca de 500 mil advogados, que têm ajudado a conscientização de direitos nos cidadãos, enquanto no Japão, apenas 18 mil.

Sobre matéria processual no Japão, os processos de inconstitucionalidade que incluem a questão do princípio de igualdade e disputam as organizações do Poder Público têm aumentado.

Ao contrário do Brasil, percebendo a tendência das Ações Diretas de Inconstitucionalidade, em muitos casos são discutidos os artigos que dispõem sobre princípios gerais, por sua ambigüidade e amplitude de sentido. Excluindo estes artigos gerais, os que tratam dos impostos, seguridade social, sindicalismo, funcionários públicos etc., enfim, os artigos manifestamente ligados aos interesses pecuniários são os mais procurados para processar a inconstitucionalidade de leis.

Um fator desta diferença em matéria processual no Japão e no Brasil consiste em que no Brasil, como País economicamente em desenvolvimento, muitas normas relacionadas às reformas econômicas lato sensu têm sido produzidas e a friç̧ão da transição, especialmente, do protecionismo ao neoliberalismo, está causando volumosos processos de constitucionalidade.

b. Em segundo lugar, vamos reexaminar o relacionamento entre o Poder Judiciário e o Poder Executivo.

Como mencionei antes, nos 258 processos das 2 mil Ações Diretas de Inconstitucionalidade, as leis ou atos normativos foram declarados inconstitucionais.

Porém, devemos recordar que o Instituto de Ação Direta de Inconstitucionalidade tem como funções a defesa dos interesses de classes ou de sindicatos e a resolução dos conflitos em nível estadual.

Das 2.198 Ações Diretas de Inconstitucionalidade processadas de 1988 até 2000,589 ações, ou seja, $27 \%$ das ações totais foram propostas por confederações sindicais ou entidades de classe de âmbito nacional.

E 567 ações, ou seja, $26 \%$ do total foram propostas por governadores. 
$\mathrm{Na}$ verdade, a maioria das leis que tiveram sido argüidas sua inconstitucionalidade vem de leis estaduais.

Considerando estes fatos, a possibilidade de que o Supremo Tribunal Federal contrarie aos outros poderes federais seria menor do que poderíamos imaginar.

Além disto, no Brasil existem severas críticas ao Supremo Tribunal Federal por sua titubeação ao enfrentar os atos do Poder Executivo. Peculiarmente, dizem que o Supremo Tribunal Federal, muitas vezes, fez concessões ao Governo atual.

Todavia, no mínimo trinta Ações Diretas de Inconstitucionalidade julgadas procedentes tiveram o presidente da República como requerido no período de outubro de 1988 até junho de 2000.

Já este número superou o das decisões de inconstitucionalidade nos 54 anos de experiência no Japão.

Portanto, pelo menos, não podemos minimizar a extrema passividade do Poder Judiciário aos outros poderes no Japão, em face da realidade brasileira.

c. Em terceiro lugar, vamos analisar a relação entre os Tribunais dentro do Poder Judiciário.

O ponto de partida é comum em ambos os países, ou seja, nenhum dos dois adota o princípio de "stare decisis"

Porém, enquanto no Brasil até é necessário buscar a ajuda da legislação para diminuir a resistência dos Tribunais inferiores que julguem constitucionalidade ou inconstitucionalidade, independentemente das decisões do Supremo Tribunal Federal, no Japão os juízes dos Tribunais inferiores propendem a obedecer a jurisprudência da Corte Suprema.

Existe a razão institucional desta obediência dos juízes japoneses.

No Japão, a Constituição atual concede a faculdade de nomear os juízes dos tribunais inferiores à Corte Suprema. O art. 80, § 1, diz:

"Os juízes dos tribunais inferiores serão designados pelo Gabinete dentro da lista das pessoas nomeadas pela Corte Suprema."

Além do mais, segundo os termos da Constituição, em letras, os juizes dos tribunais inferiores não gozam a garantia de vitaliciedade, mas apenas dez anos de mandato, com recondução.

Através deste sistema, a Corte Suprema se intromete na nomeação e promoção dos juízes. Em conclusão, os juízes que quiserem ser promovidos ou redesignados são propensos a seguir as decisõ̉es da Corte Suprema. 
Ao contrário, no Brasil o Supremo Tribunal Federal não se imiscui nem em nomeação nem em promoção dos juízes dos tribunais inferiores.

A promoção dos juízes se sujeita aos padrões de antigüidade e de merecimento, e não depende dos resultados dos julgamentos dos juízes.

Por conseqüência, os juízes brasileiros podem julgar tranqüilamente, obedecendo apenas às leis e à sua própria consciência sem se preocupar com a promoção.

Consideração Final

Como já mencionei, enquanto não-só o modelo do sistema difuso, mas, também, a família jurídica de ambos os países são similares, os usos do controle de constitucionalidade são extremamente diferentes.

Com essa condição, nós poderíamos justificar a vantagem da comparação entre o Brasil e o Japão com relação ao controle de constitucionalidade.

Agradeço muito a presença de todos nesta pequena palestra e, refletindo que minha linguagem não foi tão-sofisticada como os senhores costumam usar numa ocasião honrosa como essa, agradeço, também, pela paciência.

Muito obrigada.

São Paulo, 25 de setembro de 2001 